\title{
Effect of Epinephrine on Heart Rate and Arterial Blood Pressure of the Developing Chick Embryo
}

\author{
Lloyd E. Hoffman, Jr., and Lodewyk H. S. Van Mierop [23] \\ Departments of Pediatrics (Cardiology) and Pathology, University of Florida College of Medicine, Gainesville, Florida, USA
}

\section{Extract}

The effect of epinephrine on the heart rate and arterial pressure of 138 chick embryos ( 2 days incubation age to hatching) and 2 chicks ( 1 day old) was studied. Twenty micrograms of epinephrine administered to embryos failed to produce a significant cardiac chronotropic response. In embryos of 2-2.5 days incubation age, epinephrine caused a pronounced fall in both systolic and diastolic pressure; no pressure change was seen during the second half of incubation day 3. In all older embryos there was a marked rise in both systolic and diastolic pressures with an increase in pulse pressure. These effects were most pronounced in 4- to 6-day-old embryos.

\section{Speculation}

Systematic study of the effects of various autonomic drugs on the embryonic cardiovascular system may indicate when functional innervation occurs, and when and in which sequence $\alpha$ and $\beta$ or other receptors make their appearance. It is conceivable that at certain stages of development only $\alpha$ or $\beta$ receptors are present. If this is the case, then very young embryos in turn may provide unique subjects for the testing of newly developed autonomic drugs.

\section{Introduction}

Early studies on the effect of epinephrine on the heart rate in the developing avian or mammalian embryo are conflicting $[4,6,7,10,14,15]$. Bernard et al. [3] found only a positive chronotropic effect in rat embryos during the last few days of gestation. Markowitz [13] found a variable response in 2- to 3-day-old chick embryos, while embryos older than 6 days incubation age showed a "typical" response. Barry [2] found no rate increase in embryonic myocardial segments or whole hearts at any age if the initial rate was greater than $180 / \mathrm{min}$ and concluded that the chronotropic response of chick embryo hearts to epinephrine, regardless of age, depends on the initial rate; the lower the rate the more pronounced the response. Fingl et al. [5] reporter similar observations.
Nothing is known concerning the effect of epineplrine on the arterial blood pressure in the embryo. Van Mierop and Bertuch modified a method described by Parrish and bell [16] for measuring pressures in microcirculation and were able to measure and continuously record the arterial pressure in chick embryos from day 2 of incubation until hatching [19]. Thus, it became possible to study the effects of various autonomic drugs on arterial pressure in embryos. Since in rapidly growing embryos the cardiovascular system is continuously changing both morphologically and functionally, we have chosen to study the effects of a single clrug on embryos throughout development. This approach is practical because developmental changes, e.g., appearance of valves, innervation, and the like take place contimuously. We could neither know nor predict 
whether embryos of one or more age groups might not act in an unexpected manner to one or more drugs. The experiments reported deal with a single agent, epinephrinc.

\section{Methods}

Fertilized White Leghorn eggs of an average wcight of $60 \mathrm{~g}$ were incubated at $37.7^{\circ}$ in a forced draft incubator.

The details of the preparation of the embryos and microcannulas, the cannulation of the embryonic arteries, and the electronic circuitry used for the recording of the arterial pressure have been reported [19]. In the present study, a circuit based on these same principles [19] but built more compactly was used while the tracings were recorded [20].

All embryos were kept in the egg and pressure measurements were carried out with the embryos in situ. This insured a minimum of mechanical, physical, and chemical disturbance of the embryo and its extraembryonic membranes. With the aid of a stereomicroscope and simple micromanipulator, a glass cannula with a tip of $75-150 \mu$, could be introduced into an artery and connected by means of a rigid piece of polyethylene tubing to a transducer [21], the output of which was amplified and recorded as indicated [19]. In cmbryos of less than 5 days of age, a branch of the vitelline arterial system was used; in older embryos, a branch of the left (chorio) allantoic artery was always available. In all cases, the diameter of the vessel was much larger than that of the cannula tip.

While the arterial pressure was being recorded continuously, 5 drops of a $1 / 5000$ solution of epineplurine were deposited on the surface of the vitelline or chorioallantoic membrane. Since $1 \mathrm{ml}$, using a syringe and 22-gauge needle, calibrated out to be 50 drops, $20 \mu \mathrm{g}$ epinephrine were administered. This insured a maximal effect on the arterial pressure, and it would avoid differences in response conceivably caused by differences in absorption rate into the vascular system between younger and older specimens, since a response was elicited with amounts as little as $4 \mu \mathrm{g}$. Doses greater than $80 \mu \mathrm{g}$ produced arrhythmias and usually cardiac standstill. The time lapse between administration of the drug and change in blood pressure usually was 10-30 sec. In general, the faster response was scen in older embryos. It is of interest to note that the relatively large cannulated artery was never seen to constrict significantly after administration of epincphrine.

Satisfactory measurements (no bleeding, stable preparation, clean cannulation) were carried out on 138 embryos and on 2 1-day-old chicks. The number of embryos used in any one age group varied from 4 to 10. In most age groups arterial cannulation was easy and the results obtained were virtually identical. In some age groups, however, because of the position of the embryo in the egg and the anatomical distribution of the arteries, cannulation was more difficult, resulting in somewhat more variable results and it was necessary to use larger numbers of embryos to obtain reliable average values. After termination of the experiments, all embryos were weighed, and grouped as described previously according to stage of development [8] and embryonic weight. Underweight and malformed embryos were not included in the study.

\section{Results}

\section{Heart Rate}

The effect of epinephrine on the heart rate was inconsistent. In some embryos of any one age group the

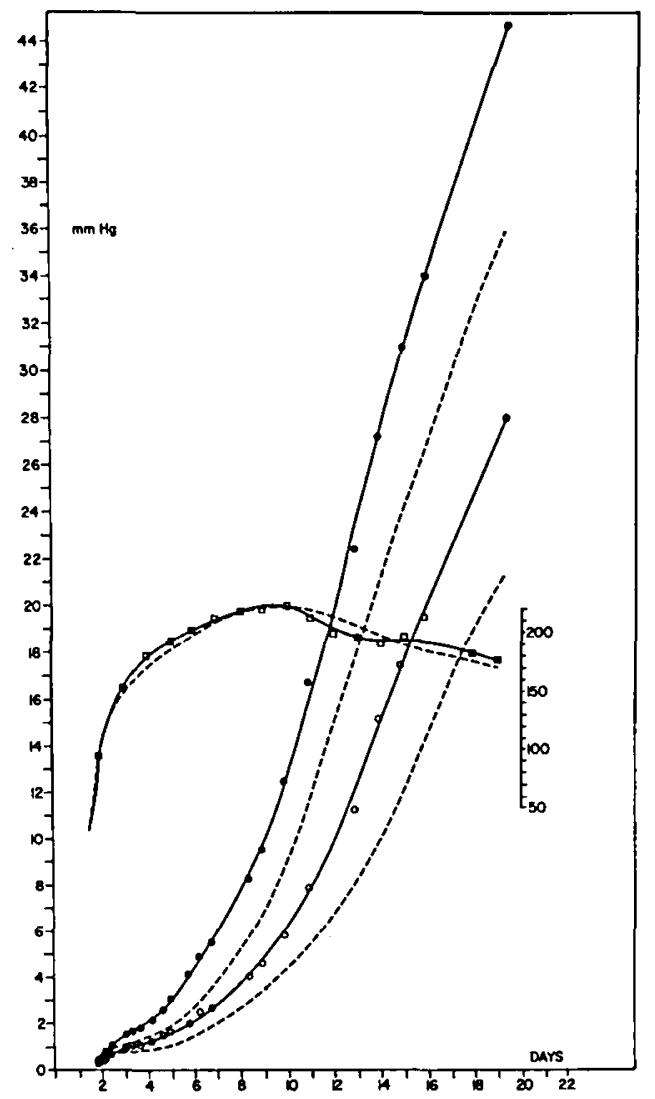

Fig. 1. Average heart rates, systolic and diastolic pressures before and after administration of epinephrine. Control values are indicated in broken lines. $\square-\square$ : Heart rate (scale on right beats per minutc). $\odot-\odot$ : Systolic pressure with epinephrine. $\bigcirc-O$ : Diastolic pressurc with cpincphrinc. 


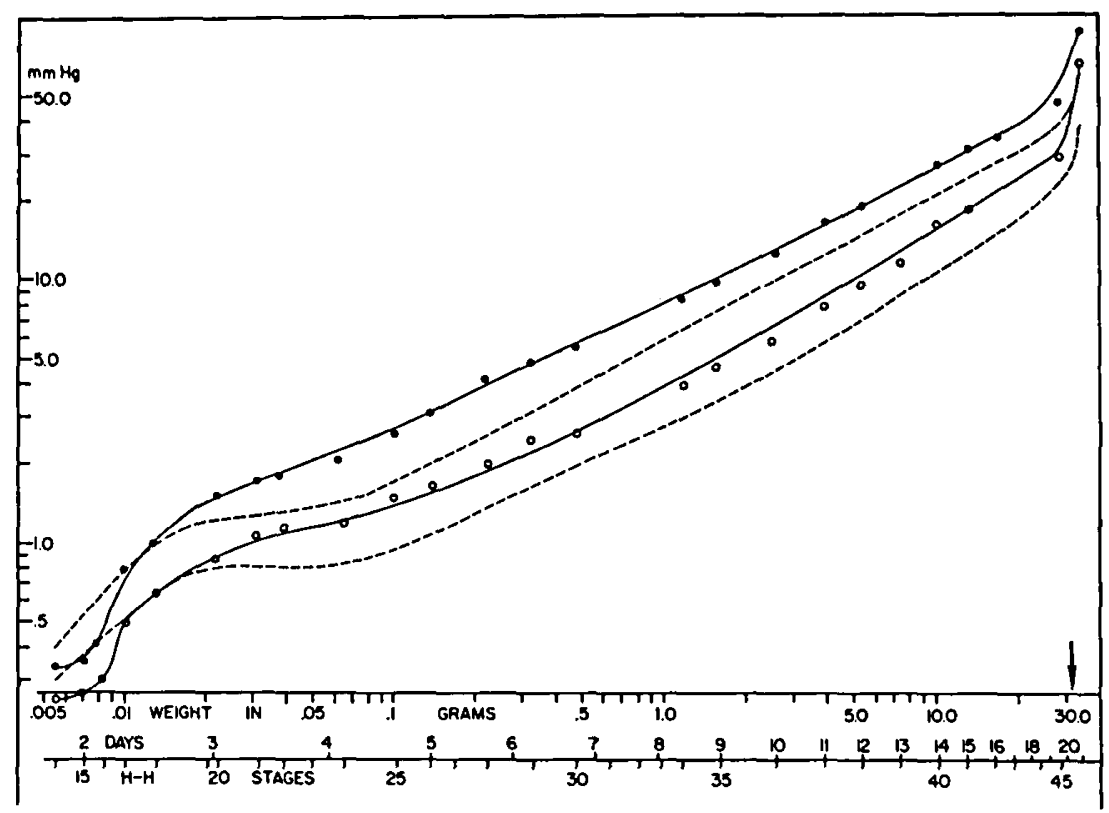

Fig. 2. Average systolic ( - - ) and diastolic (O- - $)$ pressure after administration of epinephrine plotted against embryonic weights, both on logarithmic scales. Control values are indicated by broken lines. Arrow indicates average time of hatching.

heart rate decreased; in others, there was no change or a slight increase. In only one case did the rate increase more than $10 \%$ (from 88 to $100 / \mathrm{min}$ ), and that was in one of the youngest embryos (stage 14) studied. This, as Barry [2] has suggested, was probably related to the rather slow initial rate. The decrease in rate seen on rare occasions was never more than $15 \%$. There was no significant difference in average heart rates within age groups either before or after administration of epinephrine (Fig. 1, Table I).

\section{Arterial Pressure}

In the youngest embryos (stages 14,15 , and 16) administration of epinephrine caused a pronounced fall in both the systolic and diastolic pressure and a decrease in pulse pressure (Figs. 2 and 3 ) even in those cases in which the heart rate did not change or increased slightly. In embryos of stage 17 and 18, there usually was no response; occasionally a slight fall or rise occurred. Epinephrine always produced a positive response in embryos of stage 19 or older. The greatest relative increase in both systolic and diastolic pressure was found during the second half of day 4 , and days 5 and 6 of incubation. For example, in 5-day-old embryos, the average increase in systolic pressure was $63 \%$ while the diastolic pressure increased $54 \%$. In 6-day-old embryos, these values were 57 and $50 \%$; in 11-day-old embryos, 33 and 43\%; and in 18-day-old embryos, 25 and $33 \%$. Therefore, while the pulse pressure increased in all embryos older than stage 18, the relative increase was greatest during the second half of week 1 of development. It was least pronounced in 1-day-old chicks.

In plotting the normal arterial pressure of the developing chick embryo against time, a peculiar "dip" has been noted [16] during day 4 of incubation. During this period the systolic pressure rises very little and the diastolic pressure not at all (Figs. 1 and 2). After administration of epinephrine, this dip was much less obvious, although it did not disappear completely. The full effect of epinephrine was maintained for long periods of time; however, we never saw a tendency for the arterial pressure to return to normal levels, even when the preparations were maintained up to $30 \mathrm{~min}$. It is, of course, possible that this prolonged effect was duc to continued absorption of the drug.

Statistical analyses of the changes produced by epinephrine on the arterial pressure are not given in this study. Our aim was not to determine the exact proportional changes in pressure in response to epinephrine in embryos of any one age group but rather whether such a response was a positive or negative one. Secondly, it would not be possible to quantitate the exact changes that occurred because the methodology used did not allow us to determine precisely how much drug was resorbed. 

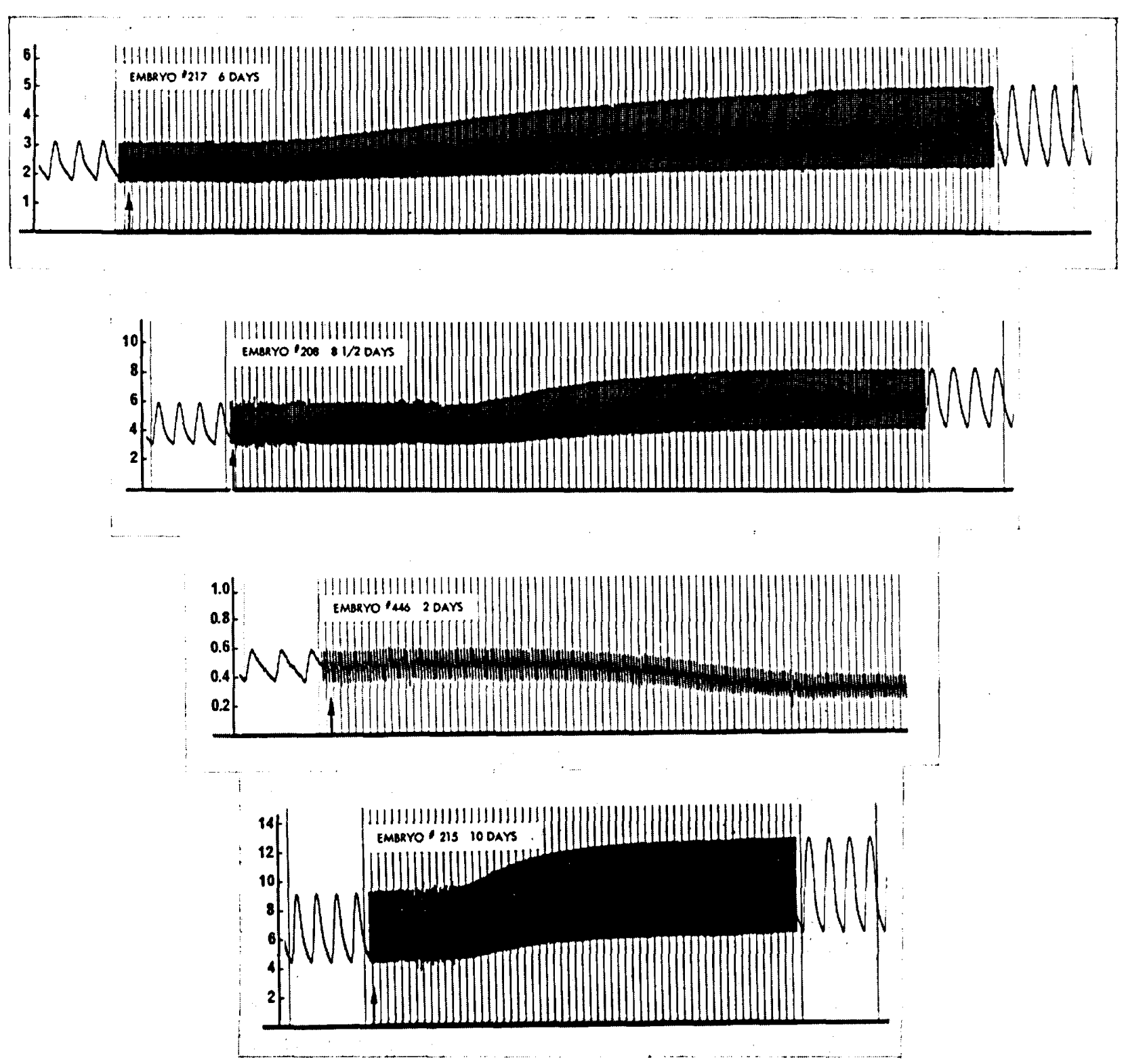

Fig. 3. Examples of tracings showing the response of the embryonic arterial pressure to epinephrine. $\Lambda$ rrows indicate time of administration of the drug. Scales in millimeters $\mathrm{Hg}$. Time lines: $1 \mathrm{sec}$. One-second sections of the tracings recorded at $25 \mathrm{~mm} / \mathrm{sec}$ paper speed were mounted at the beginning and end of the tracings to show the character of the pulse waves. Irregularities in the tracings are due to movements of the embryo.

\section{Discussion}

Our observations confirm those of Barry [2] and others $[4-6,10,15]$ that epinephrine has little effect on the heart rate of chick embryos if the initial rate is high, i.e., that of undisturbed embryos at $37.5-38^{\circ}$. Since the embryos in this study were disturbed very little, the heart rate was almost always high. The lack of any consistent response may indicate that under normal conditions the heart rate is already maximal as far as the response to epinephrine is concerned. This may be true because any vagal inhibitory effect is absent or minimal during development, or because the sympathetic nerves dominate, or because an epinephrinelike substance is present in amounts adequate to maintain a maximal chronotropic effect, but not enough to raise the arterial pressure to maximum levels. Shideman 
Table $I$. Average arterial systolic and diastolic pressurcs in chick embryos before and after administration of epinephrine

\begin{tabular}{|c|c|c|c|c|c|c|c|}
\hline \multirow{3}{*}{$\underset{\text { stage }}{\text { Embryonic }}$} & \multirow{3}{*}{ Days } & \multicolumn{6}{|c|}{ Arterial pressure, $\mathrm{mm} \mathrm{IIg}$} \\
\hline & & \multicolumn{2}{|c|}{ Control } & \multicolumn{4}{|c|}{ With epinephrine } \\
\hline & & Systolic & Diastolic & Systolic & Range & Diastolic & Range \\
\hline 14 & 1.9 & 0.4 & 0.3 & 0.3 & $0.22-0.36$ & 0.25 & $0.19-0.28$ \\
\hline 15 & 2.0 & 0.53 & 0.37 & 0.33 & $0.27-0.35$ & 0.27 & $0.21-0.30$ \\
\hline 16 & 2.1 & 0.61 & 0.45 & 0.45 & $0.39-0.51$ & 0.3 & $0.29-0.36$ \\
\hline 17 & 2.2 & 0.8 & 0.5 & 0.8 & $0.06-1.1$ & 0.4 & $0.4-0.5$ \\
\hline 18 & 2.5 & 1.0 & 0.65 & 1.0 & $0.8-1.1$ & 0.6 & $0.5-0.8$ \\
\hline 20 & 3.1 & 1.25 & 0.81 & 1.5 & $1.5-2.0$ & 0.9 & $0.6-1.2$ \\
\hline 21 & 3.4 & 1.28 & 0.81 & 1.7 & $1.6-2.0$ & 1.1 & $0.9-1.3$ \\
\hline 22 & 3.7 & 1.3 & 0.82 & 1.8 & $1.5-2.4$ & 1.1 & $0.9-1.7$ \\
\hline 24 & 4.2 & 1.5 & 0.8 & 2.1 & $1.7-2.2$ & 1.2 & $1.0-1.3$ \\
\hline 25 & 4.7 & 1.7 & 0.95 & 2.6 & $1.9-3.0$ & 1.5 & $1.0-2.1$ \\
\hline 26 & 5.0 & 1.9 & 1.1 & 3.1 & $2.6-4.2$ & 1.7 & $1.2-2.0$ \\
\hline 28 & 5.8 & 2.6 & 1.4 & 4.2 & $3.8-5.0$ & 2.0 & $1.5-2.3$ \\
\hline 29 & 6.3 & 3.3 & 1.75 & 4.9 & $3.8-5.7$ & 2.5 & $1.9-2.8$ \\
\hline 30 & 6.8 & 3.7 & 1.9 & 5.5 & $4.5-6.6$ & 2.6 & $2.2-3.3$ \\
\hline 34 & 8.4 & 5.8 & 3.1 & 8.0 & $7.2-8.2$ & 4.0 & $3.6-4.2$ \\
\hline 35 & 9.0 & 7.1 & 3.5 & 9.4 & $8.0-11.7$ & 4.6 & $3.7-6.0$ \\
\hline 36 & 10.0 & 9.2 & 4.0 & 12.5 & $11.2-15.4$ & 5.8 & $5.0-6.8$ \\
\hline 37 & 11.0 & 12.5 & 5.6 & 16.7 & $13.9-19.1$ & 7.9 & $7.6-11.7$ \\
\hline 38 & 12.0 & 15.0 & 7.2 & 19.2 & $16.6-22.5$ & 9.2 & $7.4-13.0$ \\
\hline 39 & 13.0 & 17.7 & 8.0 & 22.4 & $20.4-25.5$ & 11.3 & $8.4-15.0$ \\
\hline 40 & 14.0 & 21.2 & 10.0 & 27.2 & $23.5-29.0$ & 15.2 & $12.0-19.0$ \\
\hline 42 & 16.0 & 26.8 & 13.4 & 34.8 & $34.5-35.0$ & 19.5 & $19.0-20.0$ \\
\hline 45 & 19.5 & 36.0 & 21.5 & 44.5 & $42.0-49.0$ & 28.0 & $26.0-30.0$ \\
\hline - & 22.0 & 56.0 & 38.0 & 85.0 & $80.0-90.0$ & 63.0 & $60.0-66.0$ \\
\hline
\end{tabular}

and Ignarro [17] demonstrated the presence of small, but significant amounts of both epinephrine and norepinephrine in the egg yolk of chicken eggs during week 1 of incubation; during the first 3 days of incubation, the concentration was found to be constant; by day 4 , however, there was a distinct decrease. Their studies, using tritium-labeled tyrosine, also indicated that norepinephrine was not synthesized until day 4 of incubation, while labeled epinephrine was not detectable with the methods employed after day 6 . It appears, therefore, that epinephrine and norepinephrine, present in chick embryo hearts during week 1 of incubation, are derived from stores present in the yolk. Presumably, synthesis of these substances coincides with establishment of cardiac innervation which takes place at about day $5[1,9,11,12]$, or possibly even carlier [18].

The fall in arterial pressure scen in the youngest embryos after administration of cpinephrine was puzzling. Occasionally there was a very brief, slight rise before the pressure drop occurred. This effect could not be ascribed to reflex action because of the total absence of innervation. It does not appear to be due to a toxic effect in the usual sense, since increasing dilu- tions eventually resulted in no response at all; no concentration resulted in a positive response. In embryos of stages 17 and 18, increasing concentrations of epinephrine produced arrhythmias and death; there was never a significant fall or rise in pressure.

The marked pressor response demonstrated by the chick embryos during the second half of week 1 of incubation was interesting. As noted previously, the pressure rose very little during incubation day 4 , producing a plateau in the pressure-age graph. Administration of epinephrine makes the plateau less obvious but clocs not abolish it altogether. Although the reason for the normally occurring plateau is not known, the marked response of the pressure to epinephrine during this period suggests that it may be duc, at least in part, to depletion of available stores of catecholamines during this period of development. The response of the arterial pressure to epinephrine during weeks 2 and 3 of incubation is typical for a maximum effect of the drug. Both the systolic and diastolic pressures rise, the former more so than the latter, with a consequent rise in pulse pressure. Since the noninnervated embryonic vascular bed of the supporting membrane is much more extensive during week 2 of incubation than is 
the vascular bed within the embryo, it must be these extra embryonic vessels which are mainly responsible for the rise in pressure. This indicates a direct effect of epincphrine on the arteries of the chorioallantoic membrane.

\section{Summary}

The eflect of epinephrine on the heart rate and arterial pressure of 138 chick embryos from 2 days incubation age to hatching and 2 1-day-old chicks was studied. The lack of any consistent significant response of the heart rate, found by other investigators, was confirmed. The blood pressure was measured and recorded by intraarterial cannulation after suitable amplification and electronic correction for the damping introduced by the small diameter of the cannulas. In the youngest embryos of 2-2.5 days incubation age, epinephrine caused a pronounced fall in both systolic and cliastolic pressures. No pressure change was seen during the second half of incubation day 3 . In all older embryos there was a marked rise in both the systolic and diastolic pressures with an increase in pulse pressure.

\section{References and Notes}

1. ABEL, W.: Further observations on the development of the sympathetic nervous system in the chick. J. Anat. Pliysiol., 47: 35 (1913)

2. BARRY, A.: The effect of epinephrine on the myocardium of the cmbryonic chick. Circulation, $1: 1362$ (1950).

3. Bernard, C., Pager, J., and Gargouil., Y. M.: Sensibilité du cocur embryonnaire de rat a l'adrénaline et la noradrénaline. J. Physiol., 59(Suppl.): 350 (1967).

4. Dleorenzi, E.: Modificazioni nelle contrazioni del miocardio cmbryionale coltivato in vitro sotto l'azione di cardiocinetici. Boll. Soc. Ital. Biol. Sper., 13: 986 (1938).

5. Fingit, E., Woodburr, L. A., ANd Hecir, II. II.: Effects of innervation and drugs upon direct membrane potentials of cmbryonic chick myocardium. J. Pharmacol. Exp. Ther., 10t: 103 (1952).

6. FujII, M.: Effects of drugs on embryonic chicken heart in various stages of its development. Folia Japon. Pharmacol., 4: 309 (1927).

7. Guelin-Schedrina, A.: Réaction aux excitations du cocur de l'embryon de poulet au stade de 48 heures. C. R. Soc. Biol., 121: $214(1936)$.

8. Hamburger, V., AND Hamilton, II. L.: A series of normal stages in the development of the chick embryo. J. Morphol., SS: 49 (1951).

9. Hrs, W., JR.: Dic Entwicklung des Herznervensystems beim Wirbelthieren. Abhand, math-phys. Kl. Kgl. Sächs. Gesselsch. Wiss., 18: 1 (1891).

10. Hsu, F. Y.: The effect of adrenaline and acetylcholine on the heart ratc of the chick embryo. Chinese J. Physiol., 7: 243 (1933).

11. Jones, D. S.: Effects of acetylcholine and adrenalin on the experimentally uninnervated heart of the chicken embryo. Anat. Rec., 130: 253 (1958).

12. LfGrande, M. C., PAfF, G. H., and Boucek, R. J.: Initiation of vagal control of heart rate in the embryonic chick. Anat. Rec., 155: 163 (1966).

13. Markowitz, C.: Response of explanted embryonic cardiac tissuc to epincphrine and acetylcholine. Amer. J. Physiol., 97: 271 (1931).

14. Matsumori, T.: The effect of adrenaline on the heart of the chick embryo. Endocrinology, 13: 537 (1929).

15. Nordmann, M., AND Rüther, A.: Über die Schlagtatigkeit des explantierten Herzmuskels von Huhn and Ratte und ihre Bczichung zum Reizleitungssystem. Arch. Exp. Zellforsch., 11: 315 (1931).

16. Parrish, D., and Bell, J. W.: A tcchnique for obtaining detailed pulse pressure information from microcirculation. $J$. Appl. Physiol., 18: 189 (1963).

17. Silideman, F. E., and Ignarro, L. J.: New species may create new problems: Norepincphrine in the heart of the avian embryo. Fed. Proc., 26: 1137 (1967).

18. Szepsenwol, J., AND Bron, A.: Le premier contact du système nerveux vago-sympathique avec l'appareil cardio-vasculaire chez les embryons d'oiscaux (canard et poulet). C. R. Soc. Biol., 118: 946 (1935).

19. Van Mierop, L. H. S., ANd Bertuch, C. J., JR.: Development of arterial blood pressure in the chick embryo. Amer. J. l'liysiol., 212: 43 (1967).

20. Model 1508 Visicorder, Ioneywell, Inc., Denver, Colo.

21. Model P23Dc, Statham Instrument, Oxnard, Calif.

22. Supported by Public Health Service Grant no. HE 10912, by Graduate Clinical Pediatric Cardiovascular Training Grant no. 1-T12-HE5774, and by Developmental Physiology Training Grant no. T1-HD0054. Dr. Van Microp is the recipient of National Institutes of IIealth Carcer Development Award no. 7K3-HE21,540.

23. Requests for reprints should be addressed to: L. H. S. Van Microp, M.D., Department of Pediatrics, University of Florida College of Medicine, Gainesville, Fla. 32601 (USA).

24. Accepted for publication November 3, 1970. 